\title{
Pré-Tratamento Combinado $\mathrm{H}_{2} \mathrm{SO}_{4} / \mathrm{H}_{2} \mathrm{O}_{2} / \mathrm{NaOH}$ para Obtenção das Frações Lignocelulósicas do Bagaço da Cana-de-Açúcar
}

\author{
de Assumpção, S. M. N.; Pontes, L. A. M.; de Carvalho, L. S.; Campos, L. \\ M. A.; de Andrade, J. C. F.; da Silva, E. G.
}

Rev. Virtual Quim., 2016, 8 (3), 803-822. Data de publicação na Web: 10 de abril de 2016

http://rvq.sbq.org.br

\section{Pre-Treatment Combined $\mathrm{H}_{2} \mathrm{SO}_{4} / \mathrm{H}_{2} \mathrm{O}_{2} / \mathrm{NaOH}$ to Obtain the Lignocellulosic Fractions of Sugarcane Bagasse}

\begin{abstract}
The second generation ethanol (E2G) production process using residual lignocellulosic biomass such as bagasse and straw from sugarcane, has stimulated research to the use of different types of pretreatments that enhance the greater use of cellulose in obtaining the E2G. This process aims to reduce the crystallinity of the cellulose, favoring exposure to enzymatic attack. In this present study, sugarcane bagasse (SCB) was subjected to pre-treatment combined with dilute sulfuric acid $1.45 \%(\mathrm{v} / \mathrm{v})$, followed by delignification with hydrogen peroxide $7.5 \%(\mathrm{v} / \mathrm{v})$ and sodium hydroxide $4.0 \%(\mathrm{v} / \mathrm{v})$. Chemical characterization was performed by high performance liquid chromatography (HPLC), by diffuse reflectance infrared Fourier transform spectroscopy (DRIFTS), neutral detergent fiber (NDF), acid detergent fiber (ADF), acid detergent lignin (ADL) and scanning electron microscopy (SEM). The chemical pre-treatment evaluated preserved the cellulosic chain and allowed the removal of $85.8 \%(\mathrm{~m} / \mathrm{m})$ lignin and $70.7 \%(\mathrm{~m} / \mathrm{m})$ hemicellulose. The resulting biomass has mass percentage in cellulose of 39.5 and 45.1 as determined by HPLC techniques and ADF / NDF, respectively.
\end{abstract}

Keywords: Sugarcane bagasse; combined pre-treatment; second generation ethanol.

\section{Resumo}

O processo de produção de etanol de segunda geração (E2G), utilizando biomassas lignocelulósicas residuais, como bagaço e palha da cana de açúcar, vem fomentando a pesquisa para a utilização de diferentes tipos de pré-tratamentos que potencializem o maior aproveitamento da celulose na obtenção do E2G. Este processo visa diminuir a cristalinidade da celulose, favorecendo a exposição ao ataque enzimático. Neste trabalho, o bagaço de cana-de-açúcar (BCA) foi submetido ao pré-tratamento combinado com o ácido sulfúrico diluído 1,45\% (v/v), seguido da deslignificação com peróxido de hidrogênio $7,5 \%(\mathrm{v} / \mathrm{v})$ e hidróxido de sódio $4,0 \%(\mathrm{v} / \mathrm{v})$. A caracterização química foi realizada por cromatografia líquida de alta eficiência (CLAE), por espectroscopia por reflectância difusa no infravermelho com transformada de Fourier (DRIFTS), fibra detergente neutro (FDN), fibra detergente ácido (FDA), lignina em detergente ácido (LDA) e, por microscopia eletrônica de varredura (MEV). O prétratamento químico estudado preservou a cadeia celulósica e permitiu a remoção de $85,8 \%(\mathrm{~m} / \mathrm{m}) \mathrm{de}$ lignina e $70,7 \%(\mathrm{~m} / \mathrm{m})$ de hemicelulose. A biomassa resultante apresentou porcentagem mássica em celulose de 39,5 e 45,1, determinada pelas técnicas CLAE e FDA/FDN, respectivamente.

Palavras-chave: Bagaço de cana- de-açúcar; pré-tratamento combinado; etanol de segunda geração.

* Universidade Federal da Bahia, Escola Politécnica, Programa de Pós Graduação em Engenharia Química Rua Aristides Novis, n², Federação, CEP40210-630, Salvador-BA, Brasil.

$M$ samira.assumpcao@gmail.com

DOI: $\underline{10.5935 / 1984-6835.20160059}$

Rev. Virtual Quim. |Vol 8| | No. 3| |803-822| 


\title{
Pré-Tratamento Combinado $\mathrm{H}_{2} \mathrm{SO}_{4} / \mathrm{H}_{2} \mathrm{O}_{2} / \mathrm{NaOH}$ para Obtenção das Frações Lignocelulósicas do Bagaço da Cana-de-Açúcar
}

\author{
Samira M. N. de Assumpção, ${ }^{a}, *$ Luiz A. M. Pontes, ${ }^{a}$ Luciene S. de \\ Carvalho, ${ }^{b}$ Leila M. A. Campos, ${ }^{a}$ José C. F. de Andrade, ${ }^{b}$ Etemistocles G. \\ da Silva ${ }^{\text {b }}$ \\ a Universidade Federal da Bahia, Escola Politécnica, Programa de Pós Graduação em \\ Engenharia Química, Rua Aristides, n² 2, Federação, CEP 40210-630, Salvador-BA, Brasil.

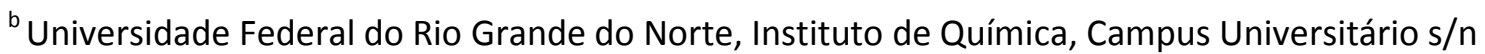 \\ Lagoa Nova, CEP 59078-970, Natal-RN, Brasil. \\ * samira.assumpcao@gmail.com
}

Recebido em 21 de agosto de 2015. Aceito para publicação em 9 de abril de 2016

\section{Introdução}

\section{Materiais e Métodos}

2.1. Preparação do Bagaço da Cana-de-Açúcar

2.2. Pré-Tratamento Químico

2.3. Métodos de Identificação e Quantificação de Frações Lignocelulósicas

2.4. Caracterização Química por Fibra Detergente Neutro (FDN), Fibra Detergente Ácido (FDA) e Lignina em Detergente Ácido (LDA) do Bagaço in natura

2.5. Caracterizações Textural e Química dos Bagaços in natura e Pré-Tratado

\section{Resultados e Discussão}

3.1. Curvas Analíticas e Análise Cromatográfica

3.2. Quantificação das Frações Lignocelulósicas do BCA in natura por CLAE e FDA/FDN e Lignina em Detergente Ácido (LDA)

3.3. Quantificação das Frações Lignocelulósicas do Bagaço Pré-Tratado

3.4. Análise por Espectroscopia por Reflectância Difusa no Infravermelho com Transformada de Fourier (DRIFTS)

3.5. Análise por Microscopia Eletrônica de Varredura (MEV)

\section{Conclusões}

\section{Introdução}

A matriz energética brasileira apresenta, atualmente, uma oferta de $42,1 \%$ de energia renovável, em que $15,4 \%$ é atribuído aos derivados da cana-de-açúcar. ${ }^{1}$ A produção do etanol de primeira geração (E1G), a partir da fermentação do caldo extraído da moagem da cana-de-açúcar, utiliza $1 / 3$ da energia 
contida na cana e o restante encontra-se na forma de resíduos agroindustriais, como o bagaço e a palha de cana-de-açúcar. Estes resíduos formam matérias-primas promissoras na produção do etanol de segunda geração $(E 2 G)^{2,3}$, pois já fazem parte da cadeia produtiva do $\mathrm{E} 1 \mathrm{G},{ }^{3,4}$ além de terem alto teor de carboidratos. Estes resíduos são utilizados no suprimento energético das usinas através dos processos de cogeração, ${ }^{a, 5}$ e servem de matéria-prima para a produção de insumos e diversos produtos destinados às indústrias de química fina, automotivas e de alimentos ${ }^{6}$, tais como compostos furânicos, E2G, biopolímeros, ácido levulínico e ácido succínico. ${ }^{6,7}$

O uso do E2G visa aumentar o volume do biocombustível, contribuindo com o suprimento do mercado automobilístico interno e a redução na importação. Além disso, é uma oportunidade de aumentar a produtividade do etanol em $40 \%$, sem alterar as áreas de plantio, nem competir com a produção de alimentos. ${ }^{7,8}$

O bagaço da cana-de-açúcar, como uma fibra vegetal, é constituído majoritariamente por três funções poliméricas: celulose (hexoses), hemicelulose (pentoses), lignina e por compostos de baixo peso molecular como extrativos e cinzas. ${ }^{9}$ Sua estrutura celular é complexa e formada por grupos químicos que se repetem em diferentes ligações carbono-carbono (C-C) e éter (C-OC), contribuindo para sua elevada recalcitrância, ou seja, resistência aos ataques químicos e microbiano. ${ }^{10}$

O reaproveitamento do bagaço na produção do E2G envolve etapas de prétratamento, que removem a lignina e hemicelulose, caracterizadas por formarem uma capa protetora natural e, assim, impedir a acessibilidade das enzimas à celulose durante o processo de sacarificação, seguida de etapas de hidrólise e fermentação, responsáveis pela conversão dos açúcares fermentescíveis (glicose) em etanol. ${ }^{2,3,11}$

a Cogeração: Processo no qual se dá a geração de energia elétrica pela queima do bagaço
O pré-tratamento é um grande desafio na produção do E2G por influenciar fortemente nas etapas subsequentes e, por isso ainda requer $\mathrm{o}$ desenvolvimento de tecnologias eficientes e de baixo custo. O desempenho da técnica a ser utilizada é avaliado em função da máxima exposição da celulose, mínima formação de inibidores de fermentação e baixo consumo de insumos e energia. ${ }^{2,3,12}$ Podem ser classificados em químicos, físicos e biológicos, mas dentre eles, o químico vem sendo o mais estudado em razão da sua viabilidade técnica e econômica. $O$ pré-tratamento químico pode ser ácido, básico ou oxidativo, diferindo pela ação do reagente e pelo mecanismo envolvido na alteração da estrutura celular. ${ }^{3,12,13}$ A combinação de soluções ácidas e básicas favorece o uso de condições amenas de temperatura e pressão, diminuindo os custos de operação. ${ }^{14} \mathrm{O}$ prétratamento com ácido sulfúrico diluído é o responsável por promover a dissolução de parte da hemicelulose, enquanto uma solução alcalina de peróxido de hidrogênio favorece a remoção da lignina e solubilização da hemicelulose remanescente, podendo extrair também óleos vegetais, proteínas e minerais que compõem a biomassa. ${ }^{11,13,15}$

O presente trabalho visou avaliar a eficiência do pré-tratamento químico combinado na estrutura recalcitrante da lignocelulose, utilizando, inicialmente, solução de ácido sulfúrico diluído $\left(\mathrm{H}_{2} \mathrm{SO}_{4}\right)$ e, em seguida, solução de peróxido de hidrogênio $\left(\mathrm{H}_{2} \mathrm{O}_{2}\right)$ em meio alcalino. A combinação destas soluções no mesmo processo está sendo relatada pela primeira vez, diferindo da literatura especializada. ${ }^{16-19}$

O ácido sulfúrico diluído é vantajoso quanto à remoção da fração hemicelulósica, com baixa degradação da celulose, ${ }^{16,17}$ e o hidróxido de sódio $^{16,18,19}$ e o peróxido de hidrogênio ${ }^{20,21}$ apresentam, respectivamente, seletividade para a remoção e oxidação da lignina, reduzindo a formação de resíduos sólidos. ${ }^{20,21}$ Além disso, o pré-tratamento combinado com estes reagentes propiciaram condições operacionais de mais baixa temperatura. 
A metodologia utilizada neste trabalho permitiu a otimização das condições de reação vigentes, em relação a literatura especializada, ${ }^{20,22,23}$ e teve como foco a minimização de custos operacionais com redução da temperatura e do tempo de reação. As etapas de caracterização química das frações lignocelulósicas foram realizadas por cromatografia líquida de alta eficiência (CLAE) a fim de determinar a composição química do bagaço, assim como fornecer resultados quantitativos das frações mássicas de lignina e hemicelulose removidas durante a etapa de pré-tratamento. As técnicas de fibra detergente ácido (FDA), fibra detergente neutro (FDN) e lignina detergente ácido (LDA) também foram utilizadas para a quantificação dos componentes majoritários do bagaço in natura. Em adição, foram realizadas análises por meio da espectroscopia por reflectância difusa no infravermelho com transformada de Fourier (DRIFTS) para a identificação dos grupos funcionais relativos a cada componente do bagaço antes e após a ação química, e microscopia eletrônica de varredura (MEV) para verificação das alterações morfológicas das fibras após o pré-tratamento.

\section{Materiais e Métodos}

\subsection{Preparação do Bagaço da Cana-de- Açúcar}

Cem gramas (100 g) de bagaço da canade-açúcar (BCA) in natura foram lavados em água corrente em ciclos de 12 horas. $\mathrm{O}$ material obtido foi seco em estufa Quimis (Q317B252) a $100{ }^{\circ} \mathrm{C}$ em ciclos de 3 horas. Este procedimento foi repetido até a estabilização da massa, obtendo-se cerca de $90 \mathrm{~g}$ do bagaço in natura, medido em balança gravimétrica. Em seguida, o bagaço foi triturado, em um moinho de facas Laboratory MILL-Model 4 e peneirado, utilizando peneiras Série Taylor entre 42-60 mesh.

\subsection{Pré-Tratamento Químico}


introduzidos em um balão contendo solução de $\mathrm{H}_{2} \mathrm{SO}_{4} \quad 1,45 \% \quad(\mathrm{v} / \mathrm{v})$ na proporção 1:10 $(\mathrm{m} / \mathrm{v})$, à temperatura de $105{ }^{\circ} \mathrm{C}$, durante 75 minutos, sob agitação constante, em evaporador rotativo Fisatom (Modelo 802 D). Em seguida, o bagaço foi transferido para um balão contendo $\mathrm{H}_{2} \mathrm{O}_{2} 7,5 \%$ (v/v) com pH 11,5, ajustado com solução de $\mathrm{NaOH} 4,0 \%(v / v)$, na proporção 1:20 (m/v) em evaporador rotativo à temperatura de $80^{\circ} \mathrm{C}$, sob agitação constante, durante 3 horas. Após o término deste procedimento, a fração sólida remanescente foi lavada com água destilada até atingir a neutralidade, e seca em estufa Quimis (Q317B252) à $100{ }^{\circ} \mathrm{C}$ até estabilização da massa. Ao final da etapa de prétratamento foram obtidos $10 \mathrm{~g}$ de bagaço pré-tratado.

\subsection{Métodos para Identificação e} Quantificação das Frações Lignocelulósicas

As frações do bagaço in natura e bagaço pré-tratado foram analisadas quanto ao teor dos carboidratos, lignina, ácidos orgânicos e inibidores de fermentação. A metodologia aplicada é uma adaptação da norma American Society for Testing Method ASTM-E $1758-01,{ }^{24}$ que quantifica a fração lignina por gravimetria e por espectroscopia UV-Visivel. Para as frações de carboidratos, ácidos orgânicos e inibidores, utilizou-se a técnica de cromatografia liquida de alta eficiência (CLAE). Todas as etapas aplicadas para a separação, identificação e quantificação das frações lignocelulósicas, para o bagaço in natura e pré-tratado, estão descritas neste tópico.

2.3.1. Separação das Frações Lignocelulósicas 
Dois gramas ( $2 \mathrm{~g}$ ) de BCA foi submetido a hidrólise com ácido sulfúrico $\left(\mathrm{H}_{2} \mathrm{SO}_{4}\right) \quad 72 \%$ $(\mathrm{v} / \mathrm{v})$ à $45^{\circ} \mathrm{C}$ por 7 minutos, em seguida, 275 $\mathrm{mL}$ de água destilada foram adicionadas à mistura obtida e, esta foi colocada em autoclave vertical da marca Phoenix modelo $\mathrm{AV}$-300 à $121{ }^{\circ} \mathrm{C}$ durante 30 minutos. $\mathrm{O}$ material resultante foi submetido a uma filtração simples em papel de filtro qualitativo Whatman $n^{\circ} 1$. A fração líquida foi utilizada para a quantificação dos carboidratos, inibidores de fermentação, (furfural e 5-hidroximetilfurfural (5HMF)) e lignina solúvel, enquanto a fração sólida foi utilizada para a quantificação do teor da lignina insolúvel e o teor de cinzas.

2.3.1.1. Quantificação da Lignina Insolúvel por Gravimetria

A fração sólida, resultante do procedimento anterior, foi lavada com $2 \mathrm{~L}$ de água destilada, transferida para pesa-filtros, previamente secos e tarados. Para a secagem foi utilizada estufa Quimis (Q317B252) à 105 ${ }^{\circ} \mathrm{C}$ até estabilização da massa. A porcentagem de lignina insolúvel foi obtida pela diferença entre as massas final e inicial, dividida pela massa seca inicial.

\subsubsection{Quantificação da Lignina Solúvel} por UV-visível

Para a determinação do teor da lignina solúvel utilizou-se a fração líquida obtida com a filtração do material hidrolisado. Uma alíquota desta fração foi analisada em espectrofotômetro UV-Vis da Shimadzu, modelo UV-2450, em comprimento de onda de $280 \mathrm{~nm}$. O cálculo da concentração da lignina solúvel foi obtido utilizando as equações 1 e 2 , em que o valor adotado para a absortividade do furfural foi igual a 146,85 $\mathrm{g}^{-1} \cdot \mathrm{cm}^{-1}$ e, para a do 5-hidroximetilfurfural (5HMF) foi de $114 \mathrm{~g}^{-1} \cdot \mathrm{cm}^{-1} \cdot{ }^{25}$

$$
C_{\text {lig }}=\frac{\left(A_{\text {lig } 280}-A_{p d 280}\right)}{\varepsilon_{\text {lig }}}
$$

\section{Equação 1}

Onde:

$C_{\text {lig: }}$ concentração da lignina solúvel $\left(\mathrm{g} \cdot \mathrm{L}^{-1}\right)$;

$A_{\text {lig280: }}$ absorbância da lignina em 280 nm;
$A_{\text {pd280: }}$ absorbância do furfural e 5-HMF e;

$\varepsilon_{\text {lig: }}$ absortividade da lignina.

$$
A_{p d 280}=C_{1} \varepsilon_{1}+C_{2} \varepsilon_{2} \quad \text { Equação 2 }
$$

Onde:

$\mathrm{C}_{1}$ : concentração do furfural $\left(\mathrm{g} \cdot \mathrm{L}^{-1}\right) ; \mathrm{C}_{2}$ : concentração do 5-HMF (g. $\left.\mathrm{L}^{-1}\right) ; \quad \varepsilon_{1}$ : absortividade do furfural; $\varepsilon_{2}$ : absortividade do 5-HMF.

2.3.1.3. Quantificação de Carboidratos, Ácidos Orgânicos e Inibidores na Fração Líquida por CLAE

As concentrações (em g. $\mathrm{L}^{-1}$ ) dos carboidratos, ácidos orgânicos e dos inibidores de fermentação foram obtidas por CLAE, utilizando um equipamento da marca Shimadzu modelo LC-10AD. Para isto foi necessária a obtenção prévia de curvas analíticas, com padrões de açúcares e inibidores. Inicialmente, foi preparada uma mistura de padrões contendo carboidratos (celobiose, glicose, xilose, arabinose) e ácidos orgânicos (ácido acético, ácido glucorônico e ácido fórmico) e, outra mistura dos inibidores de fermentação (furfural e 5-HMF), obtendose curvas distintas. Todas as análises foram 
feitas em replicatas, e, as concentrações variaram de $0-3 \mathrm{~g} \cdot \mathrm{L}^{-1}$.

As análises cromatográficas foram realizadas em Laboratório de Controle de Processos Químicos (LADABio) da Universidade Federal de São Carlos (UFSCar), São Paulo. A quantificação dos carboidratos e ácidos orgânicos presentes no bagaço foi realizada com uma coluna de separação Aminex HPX 87H (BioRad), solução de ácido sulfúrico 0,005 mol. $^{-1}$ como fase móvel, fluxo de $0,6 \mathrm{~mL} \cdot \mathrm{min}^{-1}$, temperatura do forno em 45 ${ }^{\circ} \mathrm{C}$ e, detector de índice de refração (RID-10), marca Shimadzu, modelo LC-10AD. Para a análise dos inibidores de fermentação, a fase móvel foi constituída de solução de

$$
S=\left(1-\left(\frac{m_{p} \times y_{p}}{m_{i} \times y_{i}}\right)\right) \times 100
$$

Equação 3
Onde:

S: solubilidade do componente; $\mathrm{m}_{\mathrm{p}}$ : massa do BCA pré-tratado seco (g); yp: composição mássica do componente no BCA pré-tratado; $\mathrm{m}_{\mathrm{i}}$ : massa do BCA in natura seco $(\mathrm{g}) ; \mathrm{y}_{\mathrm{i}}$ : composição do componente no BCA in natura.

2.4. Caracterização Química por Fibra Detergente Neutro (FDN), Fibra Detergente Ácido (FDA) e Lignina em Detergente Ácido (LDA) do Bagaço in natura

Primeiramente, o bagaço foi triturado e teve sua granulometria reduzida a $0,5 \mathrm{~mm}$. Em seguida, 0,55 g de bagaço (em triplicata) foram pesados em saquinhos (portaamostras) confeccionados em TNT (tecido não tecido), os quais foram posteriormente lacrados.

Os porta-amostras foram introduzidos em um equipamento da marca ANKON e submetidos ao procedimento de lavagem com detergente neutro (FDN) a fim de realizar a remoção (solubilização) de acetonitrila e água ultrapura, na proporção de 1:8 com coluna C-18 da Waters. Foram utilizados fluxo de $0,8 \mathrm{~mL} \cdot \mathrm{min}^{-1}$, temperatura ambiente, tempo de corrida de 10 minutos e detector de UV (SPD-10AV) a $274 \mathrm{~nm}$.

\subsubsection{Cálculo da Perda Mássica dos} Componentes

Os cálculos para avaliação da solubilidade ou perda mássica de cada componente no bagaço de cana de açúcar (BCA), após o prétratamento, foram realizados através da Equação 3. pectinas, proteínas, açúcares e lipídeos, resultando em um resíduo fibroso constituído essencialmente de celulose, hemicelulose e lignina. Tal processo ocorreu em um sistema fechado e sob agitação constante durante 1 hora, à temperatura de $100{ }^{\circ} \mathrm{C}$. Transcorrido o tempo necessário, a solução de FDN foi removida e adicionada água destilada ( $2 \mathrm{~L})$, na temperatura de $90{ }^{\circ} \mathrm{C}$ e, durante 5 minutos, os porta-amostras foram lavados por três vezes, substituindo-se a água destilada a cada lavagem. Em seguida, foram retirados, escorridos e deixados imersos em acetona por 5 minutos para remoção da água, e posteriormente secos em estufa à $105{ }^{\circ} \mathrm{C}$ durante 12 horas. Finalmente, foram acondicionados em dessecador e pesados, possibilitando a realização dos cálculos com as massas obtidas.

$\mathrm{Na}$ etapa seguinte, os porta-amostras foram submetidos à lavagem com detergente ácido (FDA) para quantificação do teor de hemicelulose. $O$ procedimento foi o mesmo utilizado para o detergente neutro (FDN), ocorrendo apenas a substituição do detergente ácido pelo neutro. O cálculo para determinação do teor de hemicelulose consiste na diferença entre a massa inicial 
(FDN) e final (FDA). ${ }^{26}$

Para determinação do teor de lignina (lignina em detergente ácido - LDA), as amostras ainda contidas nos porta-amostras após tratamento com a solução ácida (FDA), devidamente secas e pesadas, foram imersas em uma solução de $\mathrm{H}_{2} \mathrm{SO}_{4} \quad 72 \%(\mathrm{v} / \mathrm{v})$ à temperatura ambiente, por 3 horas, sofrendo agitação a cada 1 hora. Após o tempo necessário, os porta-amostras foram lavados com água destilada até obtenção de $\mathrm{pH}$ neutro e, imersos em béquer de $250 \mathrm{~mL}$, contendo acetona, durante 3 minutos. $\mathrm{Na}$ sequência, estes foram retirados do recipiente, colocados em uma bandeja limpa para volatilização da acetona, e logo em seguida secos novamente em estufa à temperatura de $105{ }^{\circ} \mathrm{C}$ por 12 horas, depois resfriados em dessecador e pesados. $\mathrm{O}$ cálculo para a determinação do teor de lignina é feito através da diferença entre as massas inicial (FDA) e final (após o tratamento com o ácido sulfúrico) e, o resultado, dividido pelo valor correspondente à MS (matéria seca total) pertencente ao BCA, cujo valor final é multiplicado por 100 para a obtenção em porcentagem.

Finalmente, o teor de celulose é obtido pela diferença entre os valores encontrados de FDA e lignina (respectivamente), ambos em porcentagem.

\subsection{Caracterizações Textural e Química dos Bagaços in natura e Pré-Tratado}

2.5.1. Análise por Espectroscopia por Reflectância Difusa no Infravermelho com Transformada de Fourier (DRIFTS)

A avaliação das alterações na estrutura química do BCA, antes e após o prétratamento, foi possível mediante a análise por espectroscopia de reflectância difusa no infravermelho com transformada de Fourier (DRIFTS). Os grupos funcionais predominantes na celulose, lignina e hemicelulose foram identificados mediante conhecimento prévio da estrutura do bagaço adquirida através da revisão da literatura. Os experimentos foram realizados em espectrofotômetro DRS-8000 Shimadzu com registro espectral na região $4000-400 \mathrm{~cm}^{-1}$, acumulando 45 leituras com $4 \mathrm{~cm}^{-1}$. No Quadro 1 estão representadas as bandas de absorção típicas para os compostos lignocelulósicos.

Quadro 1. Atribuições típicas em materiais lignocelulósicos por DRIFTS ${ }^{27}$

\begin{tabular}{|c|c|c|}
\hline Faixa de absorção $\left(\mathbf{c m}^{-1}\right)$ & Grupos Funcionais & Atribuição \\
\hline $3640-3200$ & $\begin{array}{r}\text { Hidroxilas }(\mathrm{OH}) \text { de álcoois, fenóis e } \\
\text { ácidos carboxilicos }\end{array}$ & Lignina e celulose \\
\hline $3000-2840$ & $\begin{array}{r}\mathrm{CH}_{2} \text { e } \mathrm{CH}_{3} \text { de grupos alquil, alifáticos } \\
\text { e aromáticos }\end{array}$ & Extrativos e celulose \\
\hline $1870-1540$ & $\begin{array}{c}\text { Carbonilas }(\mathrm{C}=\mathrm{O}) \text { de cetonas, ácidos } \\
\text { carboxilicos e de grupos acetil }\end{array}$ & Hemicelulose \\
\hline $1610-1516$ & (C=C) de anéis aromáticos & Lignina \\
\hline $1420-1330$ & Hidroxilas (OH) de fenóis & Lignina e carboidratos \\
\hline $1400-1200$ & $\begin{array}{r}\text { Hidroxilas }(\mathrm{OH}) \text { de fenóis e (C-O-C) } \\
\text { em aril-alquil-éter }\end{array}$ & Hemicelulose e lignina \\
\hline $1150-1085$ & (C-O-C) em anel de piranose & Lignina \\
\hline $900-675$ & L-H) em anéis aromáticos & Lignina \\
\hline
\end{tabular}


2.5.2. Análise por Microscopia Eletrônica de Varredura (MEV)

A microscopia eletrônica de varredura foi útil na análise das alterações morfológicas sofridas pelo bagaço da cana-de-açúcar antes e após as etapas de pré-tratamento. As análises foram realizadas no Centro de Pesquisas Gonçalo Moniz - Fundação Oswald Cruz (FIOCRUZ) em Microscópico Eletrônico modelo Denton Vaccum LLC Desk IV. Inicialmente, as amostras foram metalizadas com $10 \mathrm{~mm}$ de ouro em atmosfera de argônio por 300 segundos, com vácuo de aproximadamente $10^{-6}$ Torr em equipamento Jeol JSM-6390 1.0 com tensão de 12 kv, produzindo fótons de $4.500 \mathrm{keV}$. O ângulo de incidência foi de aproximadamente 38 deg e ampliação de 500 vezes.

\section{Resultados e Discussão}

\subsection{Curvas Analíticas e Análise Cromatográfica}

As curvas analíticas utilizadas para a quantificação dos componentes das frações lignocelulósicas, por CLAE, estão apresentadas na Figura 1. Nas Figuras $1 \mathrm{~A}$ e $1 B$ encontram-se as curvas dos açúcares e ácidos orgânicos, e em $1 \mathrm{C}$, dos inibidores. $\mathrm{Na}$
Tabela 1 encontram-se as equações das curvas obtidas e os coeficientes de determinação $\left(R^{2}\right)$, que apresentaram valores próximos de um (1), indicando ser satisfatória a linearidade dos gráficos. As equações obtidas foram utilizadas para a quantificação dos componentes do bagaço de cana, por $C L A E$, conforme cromatograma mostrado na Figura 2.

$\mathrm{Na}$ Figura 2, estão apresentados os cromatogramas obtidos na quantificação de açúcares e ácidos orgânicos, respectivamente, para os bagaços de canade-açúcar in natura, Figura 2A, e pré-tratado, Figura 2B. Em ambas os cromatogramas, pode-se observar que a glicose e a xilose apresentaram os picos de maior área, sendo estes açúcares os que possuem maior relevância, uma vez que a glicose é representativa da fração celulósica, e a xilose é predominante na lignocelulose.

O ácido acético, ácido glucurônico e a celobiose não foram quantificados, conforme mostrado no cromatograma, Figura 2 e Tabela 2, pois as concentrações destes compostos estão abaixo do limite de quantificação do equipamento.

$\mathrm{Na}$ Figura 3, estão apresentados os cromatogramas obtidos para os inibidores, HMF e furfural, utilizando a técnica CLAE, para os bagaços de cana-de-açúcar in natura, Figura 3A, e pré-tratado, Figura 3B, conforme metodologia descrita no item 2.3.1.3. 

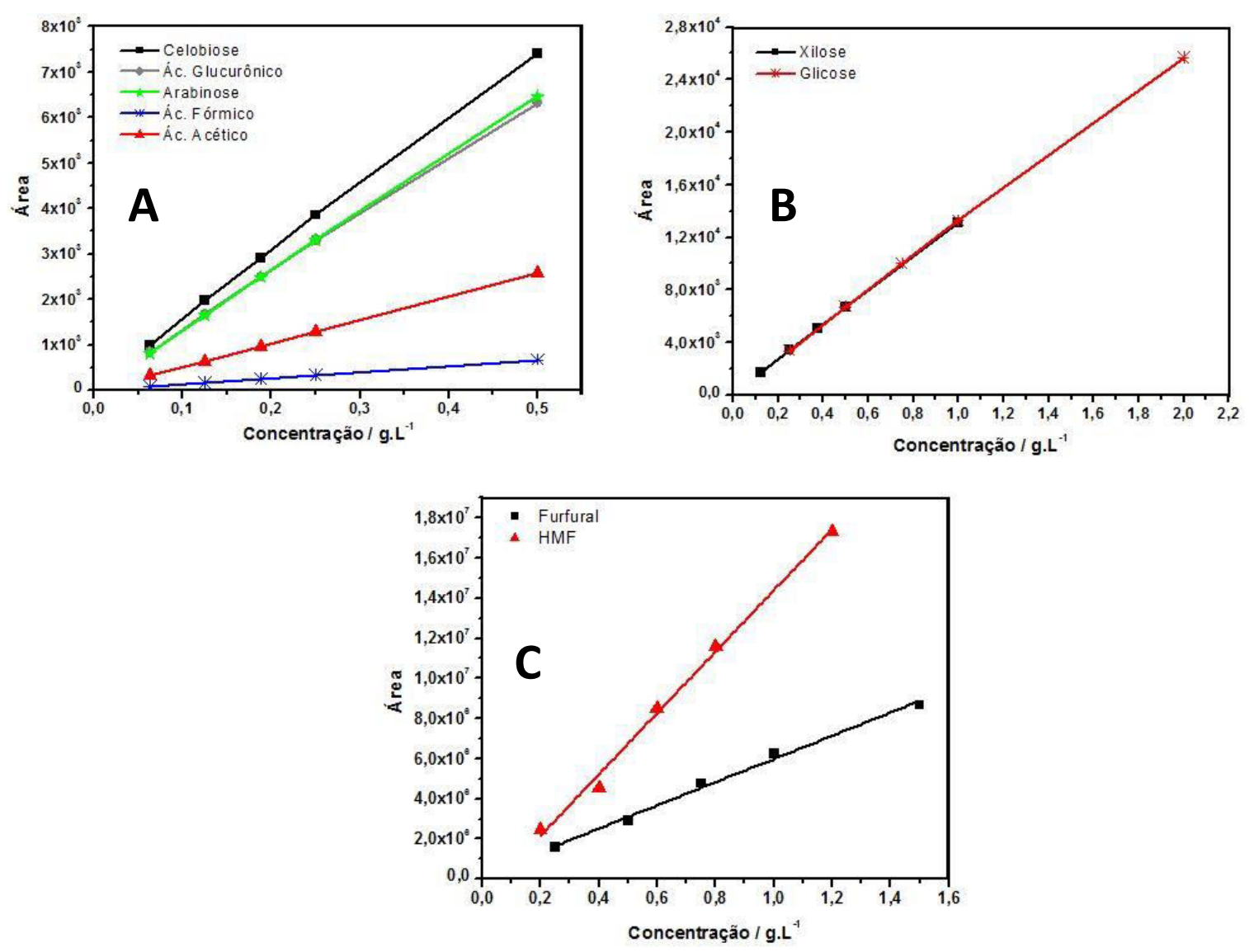

Figura 1. Curvas analíticas para quantificação dos carboidratos, ácidos orgânicos e inibidores obtidas por CLAE

Tabela 1. Equações das curvas analíticas e respectivos coeficientes de determinação $\left(\mathbf{R}^{\mathbf{2}}\right)$ para cada componente obtido por CLAE

\begin{tabular}{ccc}
\hline Composto & Equação da Reta $(\mathbf{y}=\mathbf{a x}+\mathbf{b})$ & $\begin{array}{c}\text { Coeficiente de } \\
\text { determinação } \\
\left(\mathbf{R}^{\mathbf{2}} \mathbf{)}\right.\end{array}$ \\
\hline Celobiose & $\mathrm{Y}=14610,56 \mathrm{x}+135,18$ & 0,9993 \\
Ácido glucurônico & $\mathrm{Y}=12484,69 \mathrm{x}+112,75$ & 0,9992 \\
Glicose & $\mathrm{Y}=12704,26 \mathrm{x}+377,67$ & 0,9996 \\
Xilose & $\mathrm{Y}=13031,74 \mathrm{x}+140,34$ & 0,9997 \\
Arabinose & $\mathrm{Y}=12933,52 \mathrm{x}+31,77$ & 0,9997 \\
Ácido Fórmico & $\mathrm{Y}=1352,36 \mathrm{x}-6,21$ & 0,9999 \\
Ácido Acético & $\mathrm{Y}=5179,78 \mathrm{x}-8,57$ & 0,9999 \\
Furfural & $\mathrm{Y}=5,78.10^{6} \mathrm{x}+2,1.10^{5}$ & 0,9914 \\
5-HMF & $\mathrm{Y}=1,53.10^{7} \mathrm{x}-8,91.10^{5}$ & 0,9932 \\
\hline
\end{tabular}



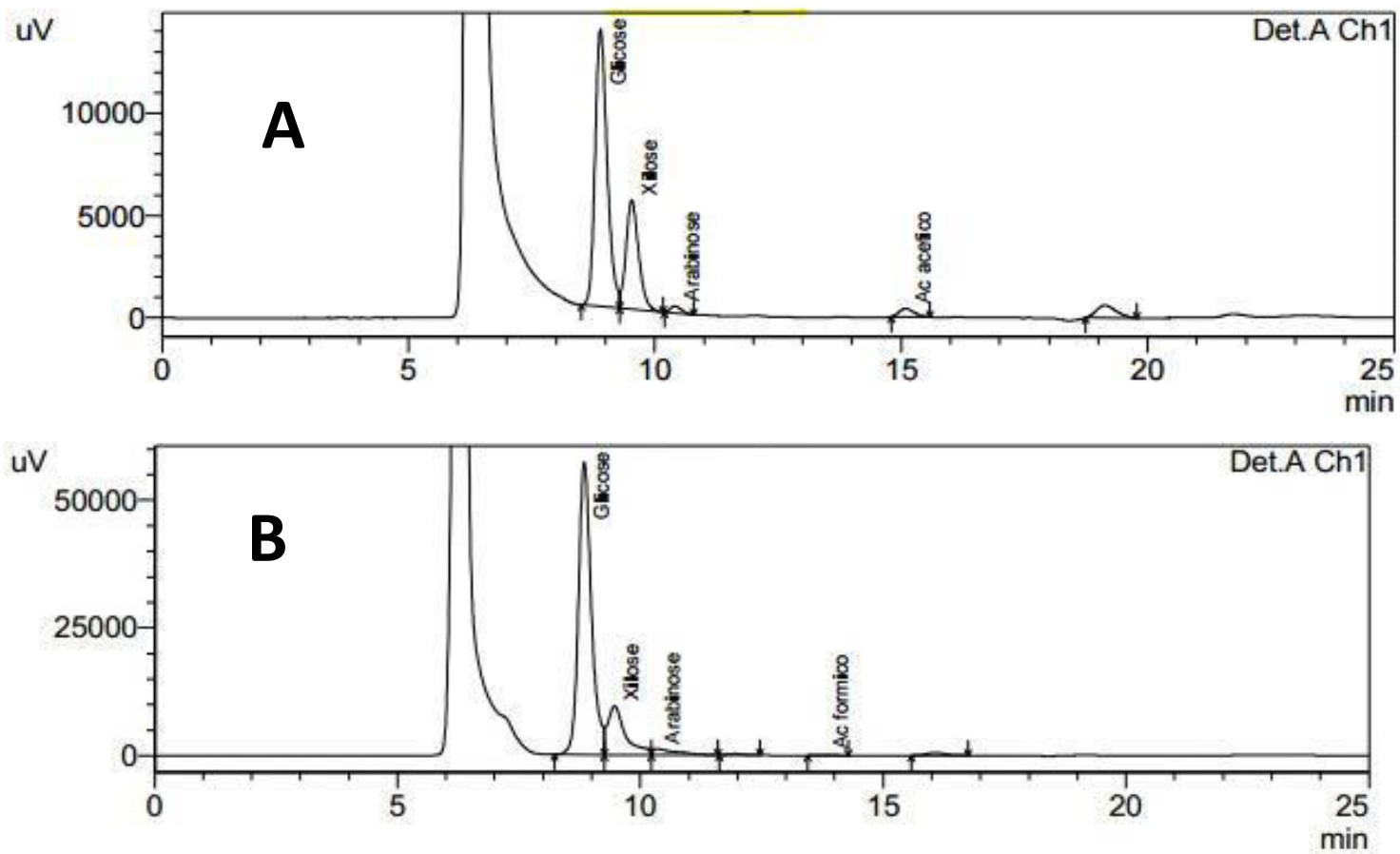

Figura 2. Cromatogramas obtidos da análise de açúcares e ácidos do bagaço de cana $(A)$ in natura e (B) pré-tratado, por CLAE
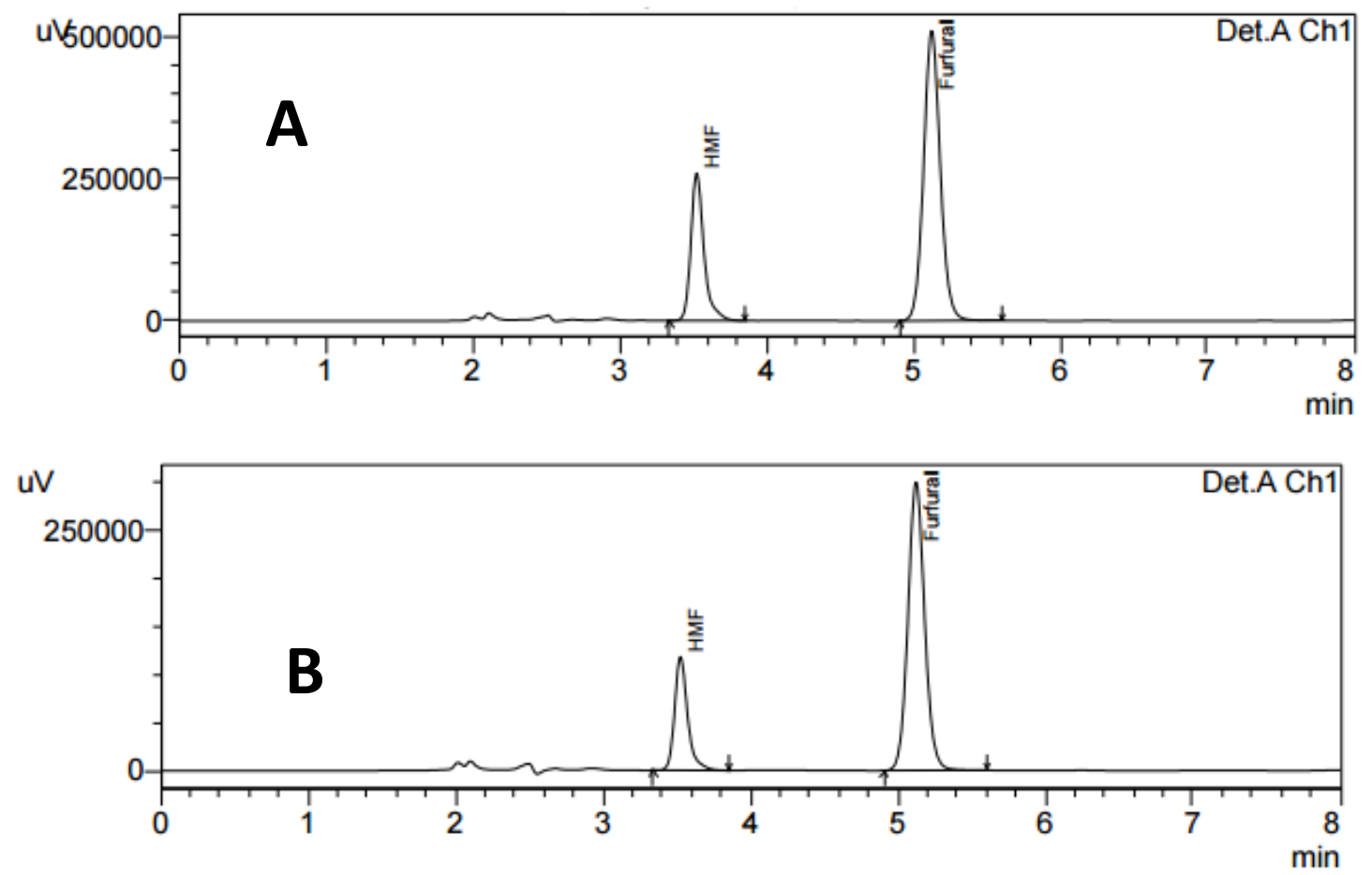

Figura 3. Cromatogramas obtidos da análise de inibidores do bagaço de cana (A) in natura e (B) pré-tratado, por CLAE 
Verificou-se que as concentrações de inibidores no bagaço são praticamente desprezíveis, frente aos açúcares, e que as concentrações destes, no bagaço in natura, são maiores que no bagaço pré-tratado, indicando a eficiência do tratamento combinado na retirada destes compostos, o que é relevante, uma vez que estes inibidores tendem a diminuir a conversão dos açúcares em outros produtos.

$\mathrm{Na}$ Tabela 2, estão apresentadas as concentrações dos açúcares, ácidos orgânicos e inibidores, obtidas pela técnica CLAE, para os bagaços in natura e pré-tratado, e seus respectivos desvios padrões.

Tabela 2. Concentrações dos carboidratos, ácidos orgânicos e inibidores do BCA in natura e pré-tratado obtidas com a técnica CLAE, por padronização externa, e, seus respectivos desvios padrões

\begin{tabular}{ccc}
\hline $\begin{array}{c}\text { Carboidratos e ácidos } \\
\text { orgânicos }\end{array}$ & \multicolumn{2}{c}{ Concentração $\left(\mathrm{g} \cdot \mathrm{L}^{-1}\right)$} \\
\cline { 2 - 3 } & BCA in natura & BCA pré-tratado \\
\hline Ácido Acético & $0,01 \pm 0,02$ & $0,00 \pm 0,00$ \\
Ácido Fórmico & $0,00 \pm 0,00$ & $0,00 \pm 0,00$ \\
Ácido Glucurônico & $0,00 \pm 0,00$ & $0,00 \pm 0,00$ \\
Arabinose & $0,00 \pm 0,01$ & $0,04 \pm 0,04$ \\
Celobiose & $0,00 \pm 0,00$ & $0,00 \pm 0,00$ \\
Glicose & $1,32 \pm 0,30$ & $3,93 \pm 0,60$ \\
Xilose & $0,24 \pm 0,09$ & $0,91 \pm 0,18$ \\
Furfural & $0,01 \pm 0,01$ & $0,00 \pm 0,00$ \\
& & $0,01 \pm 0,01$ \\
\hline
\end{tabular}

$\mathrm{N}=3$, número de replicatas.

A partir dos resultados apresentados na Tabela 2 é possível afirmar que o prétratamento utilizado neste trabalho foi eficiente em relação à disponibilização da fração celulósica, uma vez que houve um aumento no teor de açúcares, glicose e xilose, quantificado pela técnica CLAE, em relação ao bagaço in natura.

3.2. Quantificação das Frações Lignocelulósicas do BCA in natura por CLAE e FDA/FDN e Lignina em Detergente Ácido (LDA)

O estudo dos efeitos produzidos pela etapa de pré-tratamento sobre a estrutura lignocelulósica só foi possível após a quantificação prévia dos compostos majoritários (celulose, hemicelulose e lignina) do bagaço in natura, conforme Tabela 3. Os resultados de composição mássica do BCA in natura com a técnica CLAE foram obtidos a partir dos dados apresentados na Tabela 2, expressos em concentração $\left(\mathrm{g} \cdot \mathrm{L}^{-1}\right)$, e convertidos em composição mássica percentual, de acordo com a literatura especializada ${ }^{25}$, e estão mostrados na Tabela 3.

A técnica FDA/FDN, que emprega o método idealizado por Van Soest ${ }^{28}$, considera que os constituintes das plantas podem ser divididos em conteúdo celular (lipídios, compostos nitrogenados, gorduras, amido, e 
outros compostos solúveis em água) e parede celular (proteína insolúvel, hemicelulose, celulose e lignina). Este método faz uso de soluções detergentes para solubilizar o conteúdo celular e/ou hemicelulose, tendo como resíduo a fibra em detergente. Tais soluções são divididas em dois tipos: detergente neutro e detergente ácido. Utilizando-se a solução de detergente neutro solubiliza-se o conteúdo celular, restando o conteúdo insolúvel (hemicelulose, celulose e lignina), chamado então de fibra em detergente neutro (FDN). A extração com o detergente ácido, feita de forma similar a com detergente neutro, solubiliza o conteúdo celular remanescente e a hemicelulose, restando celulose e lignina. Esta extração é usada para estimar a quantidade de hemicelulose, a partir da diferença entre FDN e FDA, respectivamente, e ao mesmo tempo trata-se de uma análise preparatória para determinação de celulose e lignina, chamando-se então este resíduo final de fibra em detergente ácido (FDA).

Para a determinação da lignina em detergente ácido (LDA) foi empregada uma solução de $\mathrm{H}_{2} \mathrm{SO}_{4} 72 \%$. É importante ressaltar que o detergente ácido é capaz de remover proteínas e outros materiais solúveis neste meio que possam interferir na determinação da lignina. Desta forma, parte-se do princípio que a fibra FDA seja composta apenas de lignina e celulose, sendo esta última dissolvida pela solução de $\mathrm{H}_{2} \mathrm{SO}_{4} 72 \%$ na etapa de isolamento da lignina para sua quantificação. Porém, amostras que apresentam altos teores de material inorgânico (cinzas insolúveis) e outros materiais, como a cutina ${ }^{\mathrm{b}}$, terão seus percentuais contabilizados dentro do teor de lignina, ${ }^{29}$ uma vez que são de difícil remoção e não são solubilizados pelo detergente ácido nem pelo detergente neutro. Encontrado o percentual de lignina, foi possível quantificar o teor de celulose a partir da diferença entre

\footnotetext{
${ }^{\mathrm{b}}$ Cutina: polímero formado por muitos ácidos de cadeia longa unidos por ligações éster. A cutina está localizada na parede secundária de células vegetais.
}

o resíduo FDA (composto de celulose mais lignina) e o teor de lignina encontrado anteriormente. Os materiais indesejáveis não removidos durante a realização da análise FDN e/ou FDA foram contabilizados nas determinações subsequentes de hemicelulose, lignina e celulose. Por este motivo, os valores do teor destas substâncias apresentaram variações quando comparados aos valores obtidos por outras técnicas, como pode ser verificado na Tabela 3.

Para os componentes majoritários da biomassa, lignina, hemicelulose e celulose, os valores de composição mássica na técnica CLAE encontram-se bem próximos dos valores reportados na literatura, conforme mostrado da Tabela 3. É importante salientar que o teor de cada componente varia de acordo com as condições de plantio, colheita, armazenamento e da espécie da cana-deaçúcar.

Apesar da análise de fibras realizada através da metodologia FDN e FDA ser caracterizada pelo diferencial de solubilidade dos componentes, pode-se perceber que os resultados foram satisfatórios na quantificação dos componentes majoritários $(45,1 \%$ de celulose, $22,1 \%$ de hemicelulose e $26,1 \%$ de lignina) constituintes do BCA, uma vez que estão muito próximos da literatura e dos resultados obtidos por cromatografia líquida de alta eficiência (39,5\% de celulose, $20,5 \%$ de hemicelulose e $22,5 \%$ de lignina), conforme mostrado na Tabela 3.

3.2.1. Comparativo Entre as Técnicas de Quantificação para a Composição do BCA in natura

A quantificação das frações lignocelulósicas pela técnica do CLAE e do FDA/FDN foram realizadas em triplicatas, logo foi possível o cálculo do desvio padrão para os resultados de composição mássica obtidos. Para o cálculo do desvio padrão foi considerado a média das diferenças entre o valor de cada evento e a média central. Outra 
medida dispersiva utilizada neste trabalho foi o erro relativo entre as composições mássicas do BCA in natura. Na Tabela 4 estão mostrados os valores de desvio padrão obtidos para cada técnica avaliada neste trabalho, assim como o erro relativo entre elas. Os erros relativos para a composição mássica das frações lignocelulósicas referem- se à diferença entre os valores de composições mássicas obtidas por cada técnica, dividido pela composição de cada fração, obtida pelo CLAE. Neste cálculo tomou-se como referência a composição mássica obtida pelo CLAE, por ser uma técnica que apresenta menor erro.

Tabela 3. Composição mássica dos constituintes do BCA in natura relatados na literatura e obtidos neste trabalho

\begin{tabular}{|c|c|c|c|c|c|}
\hline \multirow[b]{2}{*}{ Fonte } & \multicolumn{4}{|c|}{ Componentes (\%) } & \multirow[b]{2}{*}{ Técnica utilizada } \\
\hline & $\begin{array}{c}\text { Celulose } \\
\text { (\%) }\end{array}$ & Hemicelulose (\%) & $\begin{array}{l}\text { Lignina } \\
\text { (\%) }\end{array}$ & $\begin{array}{c}\text { Outros } \\
(\%)\end{array}$ & \\
\hline Gómez et al ${ }^{17}$ & 37,3 & 23,6 & 25,1 & 13,9 & CLAE \\
\hline Rabelo et al $^{21}$ & 39,6 & 23,9 & 25,8 & 10,8 & CLAE \\
\hline Arruda $^{30}$ & 43,1 & 28,6 & 20,8 & 7,5 & CLAE \\
\hline Esteves $^{31}$ & 37,7 & 25,9 & 21,0 & 15,4 & CLAE \\
\hline Carvalho ${ }^{32}$ & 38,8 & 29,4 & 21,7 & 10,1 & CLAE \\
\hline Fonseca ${ }^{33}$ & 39,4 & 32,7 & 20,8 & 7,1 & CLAE \\
\hline Fuentes $^{34}$ & 37,4 & 23,7 & 25,1 & 13,9 & CLAE \\
\hline Gomes et al ${ }^{35}$ & 40,5 & 28,9 & 10,7 & 19,9 & FDA/FDN \\
\hline Neste trabalho* & 39,5 & 20,5 & 22,5 & 17,5 & CLAE \\
\hline Neste trabalho** & 45,1 & 22,1 & 26,1 & 6,7 & FDA/FDN \\
\hline
\end{tabular}

*composição obtida por meio de Cromatografia Líquida de Alta Eficiência - CLAE;

** composição obtida por meio de metodologia de análise de fibras, FDA e FDN.

Tabela 4. Erro relativo entre as análises deste trabalho

\begin{tabular}{cccc}
\hline \multirow{2}{*}{ Técnica } & \multicolumn{3}{c}{ Composição BCA in natura (\%) } \\
\cline { 2 - 4 } & Celulose & Hemicelulose & Lignina \\
\hline \multirow{2}{*}{ CLAE } & $39,5 \pm 0,7$ & $20,5 \pm 1,0$ & $22,5 \pm 0,3$ \\
FDA/FDN & $45,1 \pm 2,1$ & $22,1 \pm 2,5$ & $26,1 \pm 2,4$ \\
\hline Erro relativo & $14,3 \%$ & $8,0 \%$ & $15,8 \%$ \\
\hline
\end{tabular}

De modo comparativo, e considerando os resultados obtidos por CLAE como referência, utilizando a metodologia que segue a norma ASTM E1758-01 ${ }^{24}$, infere-se que o percentual de erro entre as técnicas utilizadas, FDA/FDN e CLAE, encontra-se na ordem de $15 \%$. Além disso, verifica-se menor desvio padrão na composição das amostras obtida com a CLAE, o que permite maior confiabilidade dos resultados.

As análises FDA/FDN são muito utilizadas nos estudos de fibras alimentares, visando à investigação nutricional de biomassas para os ruminantes. Os resultados obtidos com esta técnica, considerada de baixo custo, podem apresentar maiores desvios quanto ao conteúdo da parede celular, uma vez que é susceptível a retenção de proteínas, pectinas ${ }^{c}$ e taninos ${ }^{d}$, devido ao não fracionamento total dos constituintes da parede celular com o detergente neutro. Além disso, é limitante quanto ao teor da fração hemicelulósica real presente no material em virtude da solubilização incompleta da hemicelulose com o tratamento com detergente ácido. Por 
se tratar de uma técnica gravimétrica, podem ocorrer erros grosseiros no que se refere à manipulação excessiva dos analistas, tomada de alíquotas e erros de pesagem, que diminuem a precisão dos resultados. Em contrapartida, a cromatografia líquida de alta eficiência, por se tratar de uma técnica cujo equipamento é automatizado requerendo menor intervenção do analista, é caracterizada pela grande precisão e elevada eficiência na separação dos compostos com uma alta resolução, entretanto apresenta custo elevado.

\subsection{Quantificação das Frações Lignocelulósicas do BCA Pré-Tratado}

Na Tabela 5 estão apresentados os dados comparativos da composição química do bagaço in natura e do bagaço pré-tratado obtidos por CLAE, conforme ASTM E1758$01 .^{24}$ Ressalta-se que os valores referentes aos ácidos orgânicos, furfural e 5hidroximetilfurfural já estão incorporados na composição da celulose e hemicelulose, uma vez que são provenientes da degradação destes carboidratos. É possível notar um aumento da concentração, percentual mássica, da celulose no bagaço pré-tratado, em virtude da remoção das frações de lignina e hemicelulose. Essa resposta é positiva por tornar a celulose mais disponível para etapas posteriores de sacarificação.

Com a Equação 3 mencionada no item 2.3.2, calculou-se a perda mássica (solubilidade) de cada componente do bagaço antes e após o pré-tratamento, dispostos na Tabela 6 .

Tabela 5. Composição percentual mássica do BCA in natura e pré-tratado obtido por CLAE

\begin{tabular}{cccc}
\hline \multirow{2}{*}{$\begin{array}{c}\text { Componentes do } \\
\text { bagaço }\end{array}$} & \multicolumn{3}{c}{ Composição mássica (\%) } \\
\cline { 2 - 4 } & BCA in natura & $\begin{array}{c}\text { BCA após o pré-tratamento } \\
\text { ácido }\end{array}$ & $\begin{array}{c}\text { BCA após o pré-tratamento } \\
\text { ácido e alcalino combinado }\end{array}$ \\
\hline Celulose & 39,5 & 46,2 & 67,8 \\
Hemicelulose & 20,5 & 13,1 & 12,5 \\
Lignina & 22,5 & 24,7 & 6,6 \\
Outros & 17,5 & 16,0 & 13,1 \\
\hline
\end{tabular}

Tabela 6. Solubilização mássica (\%) dos componentes majoritários do bagaço após os prétratamentos ácido, e ácido e alcalino combinado

\begin{tabular}{ccc} 
Componentes & BCA após o Pré-tratamento ácido & $\begin{array}{c}\text { BCA após o pré-tratamento } \\
\text { ácido e alcalino combinado }\end{array}$ \\
\hline Celulose & 5,6 & 17,5 \\
Hemicelulose & 48,3 & 70,7 \\
Lignina & 13,4 & 85,8 \\
\hline
\end{tabular}


Conforme pode ser observado nas Tabelas 5 e 6 , houve um enriquecimento do teor de celulose em $67,8 \%(\mathrm{~m} / \mathrm{m})$ em relação à biomassa in natura, com significativa solubilização de $70,7 \% \quad(\mathrm{~m} / \mathrm{m})$ da hemicelulose e, $85,8 \%(\mathrm{~m} / \mathrm{m})$ da lignina. A remoção de pelo menos $50 \%$ da hemicelulose já é suficiente para aumentar sensivelmente a eficiência da etapa da hidrólise enzimática. ${ }^{10} \mathrm{Na}$ Tabela 6 , observa-se que o pré-tratamento com solução ácida apresentou uma maior seletividade quanto a remoção da hemicelulose, conforme indicado por Alvira et al. ${ }^{16}$ e Carvalho et al. ${ }^{36}$ Além disso, é possível verificar que a perda mássica de celulose foi $17,5 \%$, após o pré-tratamento combinado. Nada et al. ${ }^{14}$ relata que a celulose é composta por uma fase $15 \%$ amorfa que é mais facilmente hidrolisada e solubilizada. A perda mássica sinalizada neste estudo aponta que a fase amorfa da celulose foi degradada com a ação do pré-tratamento combinado.

A perda mássica da lignina, por sua vez, foi bastante expressiva. Os fenóis, derivados da lignina, inibem a ação de microorganismos nas etapas de hidrólise e fermentação. Logo, a redução da lignina é positiva e indica que a biomassa pré-tratada está mais adequada para a produção de E2G. Os principais derivados da lignina são o ácido 4-hidroxibenzóico, vanilina, catecol e o seringaldeído, ácido vanílico e ácido ferúlico. ${ }^{37}$

$\mathrm{Na}$ literatura foram encontrados trabalhos que estudaram o pré-tratamento combinado de materiais lignocelulósicos, Wang et $a l^{38}$, ao realizar o pré-tratamento combinado do bagaço com ácido fosfórico seguido de solução de peróxido de hidrogênio alcalino, obtiveram uma perda mássica em celulose de $29 \%(\mathrm{~m} / \mathrm{m})$, com solubilização mássica de $74,4 \%$ de hemicelulose e $76,4 \%$ de lignina. Rezende et al. $^{39}$ estudaram o pré-tratamento do bagaço da cana com o ácido sulfúrico diluído seguido do uso de solução de hidróxido de sódio, resultando na remoção mássica de $85 \%$ de lignina e $96 \%$ hemicelulose e, degradação de $30 \%(\mathrm{~m} / \mathrm{m})$ da celulose. $\mathrm{Kim}$ e $\mathrm{Kim}^{40}$ obtiveram uma deslignificação de $70 \%(\mathrm{~m} / \mathrm{m})$ e remoção de $83 \%(\mathrm{~m} / \mathrm{m})$ de hemicelulose, ao pré-tratar a fibra de palma com ácido sulfúrico diluído, seguido de solução de hidróxido de sódio. Chen et al. ${ }^{41}$ ao pré-tratar o BCA com o peróxido de hidrogênio seguido de explosão a vapor, conseguiram solubilizar $60,9 \%(\mathrm{~m} / \mathrm{m})$ da hemicelulose e remover $75,7 \%(\mathrm{~m} / \mathrm{m})$ da lignina. Estes resultados permitem comprovar que os percentuais obtidos neste trabalho são bastante promissores para o pré-tratamento de materiais lignocelulósicos, em particular, o bagaço da cana-de-açúcar.

\subsection{Análise por Espectroscopia por Reflectância Difusa no Infravermelho com Transformada de Fourier (DRIFTS)}

As análises realizadas por DRIFTS possibilitaram a observação das alterações estruturais, conforme mostrado na Figura 4. 


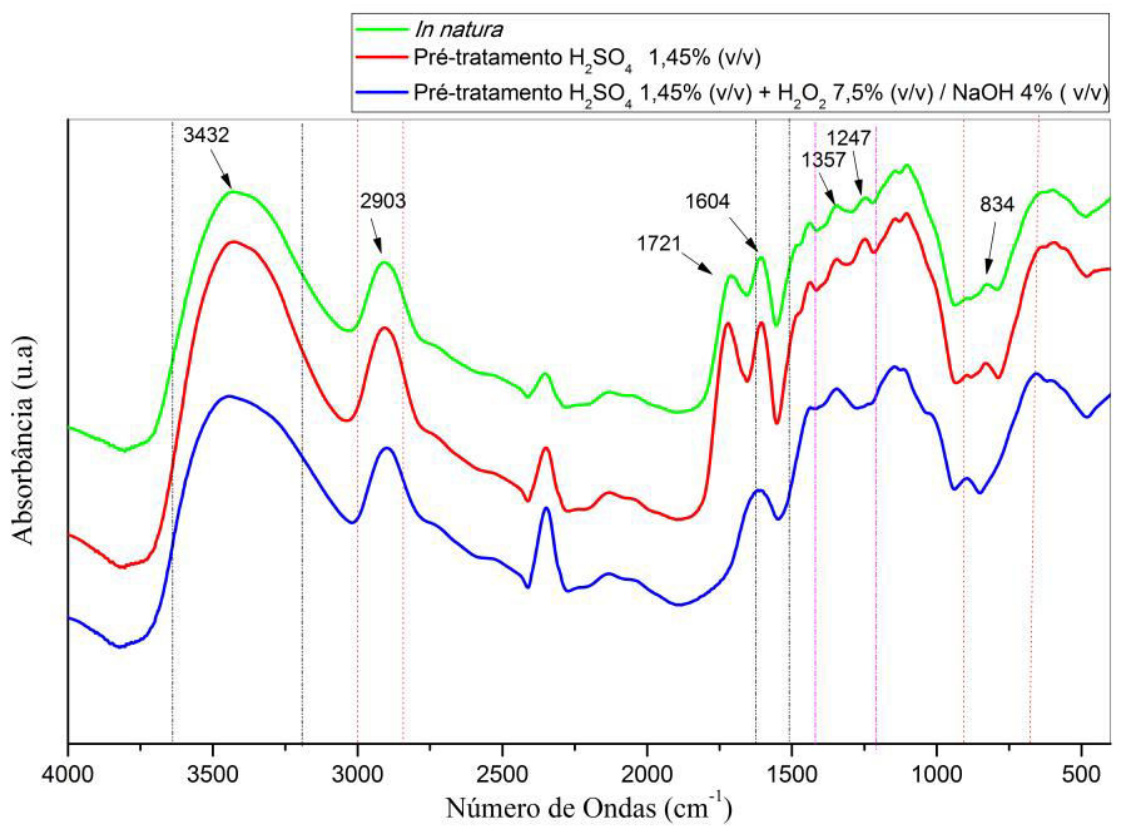

Figura 4. Espectros do DRIFTS das amostras de bagaço in natura e pré-tratadas

$\mathrm{Na}$ Figura 4, que apresenta os espectros do BCA in natura, pré-tratado com $\mathrm{H}_{2} \mathrm{SO}_{4} \mathrm{e}$ pré-tratado combinado $\quad\left(\mathrm{H}_{2} \mathrm{SO}_{4}+\right.$ $\mathrm{H}_{2} \mathrm{O}_{2} / \mathrm{NaOH}$ ), é perceptível a existência de bandas que podem ser atribuídas aos componentes majoritários da biomassa. A celulose é representada por duas bandas específicas, sendo a primeira, em $3432 \mathrm{~cm}^{-1}$ pela vibração dos grupos hidroxila $(\mathrm{OH})$ dos álcoois, fenóis e ácidos carboxílicos, e a segunda, em $2903 \mathrm{~cm}^{-1}$ referente às vibrações dos grupos metil $\left(\mathrm{CH}_{3}\right)$ e metileno $\left(\mathrm{CH}_{2}\right)$, em compostos alifáticos. ${ }^{27,30} \mathrm{Em}$ ambas regiões ficou evidenciada uma perda pouco significativa deste componente no bagaço pré-tratado. Este comportamento ratifica os resultados anteriores da baixa solubilização da celulose, preservando assim a fração de interesse para a obtenção do E2G a partir da sua hidrólise.

A lignina e a hemicelulose podem ser observadas nas demais bandas apontadas nos espectros. Os grupos funcionais presentes na cadeia hemicelulósica são representados pelos picos em $1721 \mathrm{~cm}^{-1}$ que se referem ao estiramento das carbonilas $(\mathrm{C}=0)$ provenientes de vibrações de ácidos carboxílicos e cetonas e, em $1247 \mathrm{~cm}^{-1}$, característico do estiramento simétrico da ligação (C-O-C) da lignina. Zhao et al., ${ }^{42}$ em estudo similar, também indicou as bandas supracitadas referentes à hemicelulose.

A alteração estrutural da lignina, por sua vez, é evidenciada em $1604 \mathrm{~cm}^{-1}$ referente ao estiramento da ligação $(C=C)$ do anel aromático e, em $1357 \mathrm{~cm}^{-1}$, atribuída a vibração da deformação angular de hidroxilas $(\mathrm{OH})$ ligadas a grupos fenólicos. Outra evidência da presença da lignina refere-se à banda em $834 \mathrm{~cm}^{-1}$ relativa à vibração de deformação de ligações do tipo carbonohidrogênio $(\mathrm{C}-\mathrm{H})$ provenientes de compostos aromáticos. ${ }^{27}$ As atribuições destas bandas espectrais também foram citadas por Yang et al. $^{43}$ Com os espectros apresentados, observa-se nestas cinco últimas bandas uma redução do sinal analítico no bagaço prétratado quando comparado ao bagaço in natura. Os resultados confirmam que houve a remoção de frações de lignina e hemicelulose no bagaço após o prétratamento. 


\subsection{Análise por Microscopia Eletrônica de Varredura (MEV)}

O pré-tratamento do bagaço promove alterações morfológicas que garantem a menor cristalinidade da celulose, com consequente aumento da acessibilidade das enzimas na hidrólise. A Figura 5 apresenta as imagens obtidas com a Microscopia Eletrônica de Varredura (MEV) das amostras de bagaço in natura $(5 \mathrm{~A})$, após o prétratamento ácido (5B) e, após o prétratamento com ácido e alcalino combinado (5C).
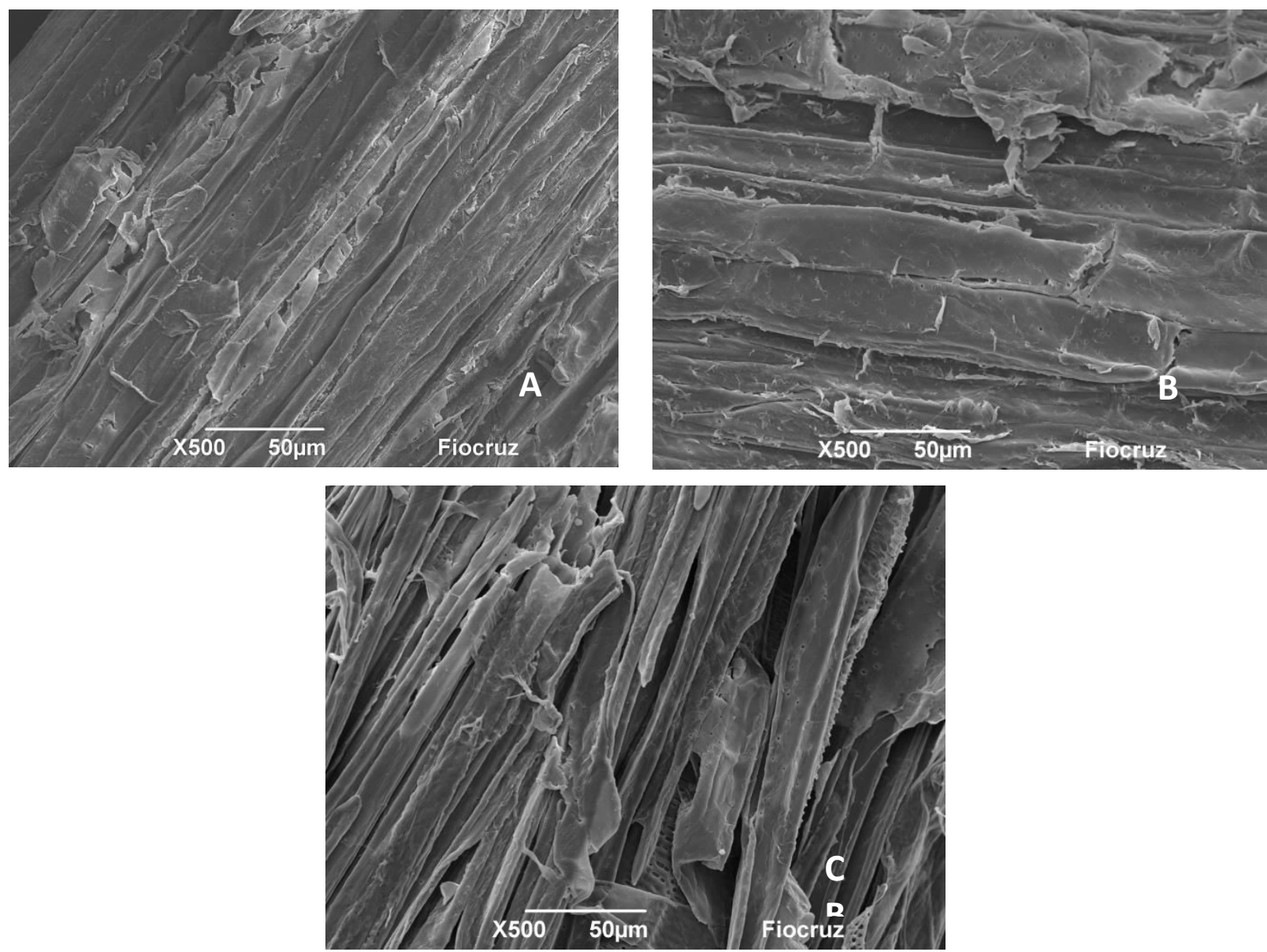

Figura 5. Micrografia Eletrônica de Varredura (MEV) das amostras de bagaço da cana (A) sem pré-tratamento (in natura), (B) pré-tratamento com solução de ácido sulfúrico e (C) prétratamento com ácido sulfúrico e peróxido de hidrogênio em meio alcalino

Observa-se na Figura 5A, uma estrutura vegetal bem organizada com fibras lisas, compactas e sem nenhuma ruptura, características do bagaço sem o prétratamento. Isso ocorre devido a presença da camada protetora formada pela lignina e hemicelulose. $O$ bagaço submetido ao prétratamento com ácido sulfúrico (Figura 5B) não apresentou alterações morfológicas significativas, apenas formação de fissuras na superfície. Após o pré-tratamento ácido e alcalino combinado, Figura $5 \mathrm{C}$, verificou-se a ocorrência de dois tipos de eventos: a abertura de fendas ou canais, e a formação de uma parede celular estratificada. Para Rezende et al. ${ }^{39}$ as várias camadas formadas indicam uma fibra com maior área superficial, enquanto as fendas caracterizam uma maior porosidade da fibra.

A partir destas micrografias infere-se que o pré-tratamento contribuiu para maior 
desorganização física das fibras, resultando assim em uma maior acessibilidade para as enzimas durante a hidrólise enzimática na obtenção do E2G.

\section{Conclusões}

O pré-tratamento com ácido sulfúrico combinado com peróxido de hidrogênio em meio alcalino foi bem sucedido. A novidade deste trabalho consiste na ação dos três reagentes em conjunto, que resultou em uma fração rica em celulose, com remoção significativa da lignina e hemicelulose, caracterizadas por serem estruturas recalcitrantes e prejudiciais à etapa de hidrólise enzimática da celulose na produção do etanol de segunda geração. Portanto, a combinação de soluções ácidas e alcalinas permitiu maior acessibilidade à celulose em um pré-tratamento sob condições amenas de concentração de reagentes, reduzindo assim os custos de produção.

As limitações quanto ao fracionamento dos constituintes da parede celular do material lignocelulósico, assim como, a possibilidade da solubilização parcial da cadeia hemicelulósica durante a análise composicional do BCA por meio da análise de fibras (FDN e FDA), são justificativas pertinentes para os valores encontrados não estarem tão exatos quando comparados com outras técnicas de determinação composicional. Porém, devido à simplicidade e baixo custo desta análise, frente a outras técnicas, como a cromatográfica líquida de alta eficiência (CLAE), a análise de fibras apresenta grande praticidade, podendo ser utilizada como alternativa à norma ASTM E1758-01, para a quantificação de materiais utilizados para produção do E2G. A técnica CLAE assegura um menor erro na quantificação das frações lignocelulósicas, sendo a técnica mais difundida para esta metodologia.

\section{Agradecimentos}

Os autores agradecem o apoio das
instituições MCT/FINEP, REDE DE
COMBUSTÍVEIS, CAPES pelas bolsas, à
UFSCar, UFRN, UFBA e CPGM - FIOCRUZ pela
caracterização química, e à UNIFACS pela
disponibilidade dos laboratórios.

\section{Referências Bibliográficas}

${ }^{1}$ Sítio do Ministério de Minas e Energia (MME). Disponível em: $<$ http://www.mme.gov.br/web/guest/public acoes-eindicadores/pde? 20 displayStyle=descriptiv e\&p p id=20>. Acesso em: 5 março 2015.

${ }^{2}$ Raele, R.; Boaventura, J. M. G.; Fischmann, A. A.; Sarturi, G. Scenarios for the second generation ethanol in Brazil. Technological Forecasting \& Social Change 2014, 87, 205. [CrossRef]

${ }^{3}$ Sousa-Aguiar, E. F.; Appel, L. G.; Zonetti, P. C. Fraga; A. C.; Bicudo, A. A.; Fonseca, I. Some important catalytic challenges in the bioethanol integrated biorrefinary. Catalysis Today 2014, 234, 13. [CrossRef]

${ }^{4}$ Moraes, B. S.; Zaiat, M.; Bonomi, A. Anaerobic digestion of vinasse from sugarcane ethanol production in Brazil: Challenges and perspectives. Renewable and Sustainable Energy Reviews 2015, 44, 888. [CrossRef]

${ }^{5}$ Vaz Júnior, S.; Estratégias para o uso de biomassa em química renovável, 1a. Ed., Embrapa Agroenergia: Brasília, 2012. [Link]

${ }^{6}$ Cherubini, F. The biorefinary concept: Using biomass instead of oil for producing energy and chemicals. Energy Conversion and Management 2010, 51, 1412. [CrossRef]

${ }^{7}$ Alvim, J. C.; Alvim, F. A. L. S.; Sales, V. H. G.; Sales, P. V. G.; Oliveira, E. M.; Costa, A. C. R. Biorrefinarias: Conceito, classificação e matérias primas e produtos. Journal of Bioenergy and Food Science 2014, 3, 61. [Link] 
${ }^{8}$ Morais, A. P. S.; Broetto, F. Pré-hidrólise ácida de bagaço de cana-de-açúcar e sua caracterização físico-química. Energia na Agricultura 2012, 27, 1. [CrossRef]

${ }^{9}$ Santos, F. A.; Queiróz, J. H.; Colodette, J. L.; Fernandes, S. A.; Guimarães, V. M.; Rezende, S. T. Potencial da palha de cana-de-açúcar para produção de etanol. Química Nova 2012, 35, 1004. [CrossRef]

${ }^{10}$ Agbor, V. B.; Cicek, N.; Sparling, R.; Berlin, A.; Levin, D. B. Biomass pretreatment: Fundamentals toward application. Biotechnology Advances 2011, 29, 675. [CrossRef] [PubMed]

${ }^{11}$ Assumpção, S. M. N.; Dissertação de Mestrado, Universidade Federal da Bahia, 2015.

${ }^{12}$ Chaturvedi, V.; Verma, P. An overview of key pretreatment process employed for bioconversion of lignocellulosic biomas sinto biofuels and value added process. 3 Biotech 2013, 3, 415. [CrossRef]

${ }^{13}$ Brouder, G.; Yau, E.; Badal, K.; Collier, J.; Ramanchandran, K. B.; Ramakrishnan, S. Chemical and physicochemical pretreatment of lignocellulosic biomass: A review. Enzyme Research 2011, 2011, 1. [CrossRef] [PubMed] ${ }^{14}$ Nada, A. A. M. A.; El-Kady, M. Y.; El- Sayed, E. S.A. B.; Amine, F.M. Preparation and characterization of microcrystalline cellulose (MCC). BioResources 2009, 4, 1359. [Link]

${ }^{15}$ Canilha, L.; Chandel, K. A.; Milessi, T. S. S; Antunes, F. A. F.; Freitas, W. L. C.; Felipe M. G. A.; da Silva, S. S; Bioconversion of Sugarcane Biomass into Ethanol: An overview about composition, pretreatment methods, detoxification of hydrolysates, enzymatic saccharification, and ethanol fermentation. Journal of Biomedicine and Biotechnology 2012, 2012, 1. [CrossRef] [PubMed]

${ }^{16}$ Alvira, P.; Tomás-Pejó E.; Ballesteros, M.; Negro, M. J. Pretreatment technologies for an efficient bioethanol production process based on enzymatic hydrolysis: A review. Bioresource Technology 2010, 101, 851. [PubMed]

${ }^{17}$ Gómez Sandra, M. R.; Rafael, R. A.; Carlos, G. S.; Costa, A. C.; Marciel Filho, R. Pretreatment of sugar cane bagasse with phosphoric and sulfuric diluted acid for fementable sugars production by enzimatic hydrolysis. Chemical Engineering Transactions 2010, 20, 321. [CrossRef]

${ }^{18}$ Chandel, A. K.; Antunes, F. A. F.; Anjos, V.; Bell, M. J. V.; Rodrigues, L. N.; Polikarpov, I.; Azevedo, E. R.; Bernardinelli, O. D.; Rosa, C. A.; Pagnocca, F. C.; Silva, S. S. Multi-scale structural and chemical analysis of sugarcane bagasse in the process of sequential acidbase pretreatment and ethanol production by Scheffersomyces

shehatae and Saccharomyces cerevisiae. Biotechnology for Biofuels 2014, 7, 1. [Link]

${ }^{19}$ Ramadoss, G.; Muthukumar, K. Influence of dual salt on the pretreatment of sugarcane bagasse with hydrogen peroxide for bioethanol production. Chemical Engineering Journal 2015, 260, 178. [CrossRef]

${ }^{20} \mathrm{Su}$, Y.; Du, R.; Guo, H.; Cao, M.; Wu, Q.; Su, R.; Qi, W.; He. Z. Fractional pretreatment of lignocellulose byalkaline hydrogen peroxide: Characterization of its major components. Food and Bioproducts Processing 2015, 94, 322. [CrossRef]

${ }^{21}$ Rabelo, S. C.; Andrade, R. R.; Maciel Filho, R.; Costa, A. C. Alkaline hydrogen peroxide pretreatment, enzymatic hydrolysis and fermentation of sugarcane bagasse to ethanol. Fuel 2014, 136, 349. [CrossRef]

${ }^{22}$ Terán-Hilares, R.; Reséndiz, A. L.; Martínez, R. T.; Silva, S. S.; Santos, J. C. Successive pretreatment and enzymatic saccharification of sugarcane bagasse in a packed bed flowthrough column reactor aiming to support biorefineries. Bioresource Technology 2016, 203, 42. [CrossRef]

${ }^{23}$ Bluhm, K.; Heger, S.; Agler, M. T.; Maletz, S.; Schäffer, A.; Seiler, T. B.; Angenent, L. T.; Hollert, $H$. In Assessment of the Ecotoxicological and Environmental Effects of Biorefineries, in The Role of Green Chemistry in Biomass Processing and Conversion; Xie, H.; Gathergood, N., eds.; John Wiley \& Sons, Inc.: Hoboken, 2012, Cap. 15.

${ }^{24}$ American Society for testing and Materials Method. ASTM E1758-01: Standard Test Method for Determination of Carbohydrates in Biomass by High Performance Liquid Chromatography. Current edition approved June 1, 2015. Published July 2015. Originally approved in 1995. Last previous edition 
approved in 2007 as E1758-01(2007). West Conshohocken, 2015. [Link]

${ }^{25}$ Gouveia, E. R.; Nascimento, R. T.; SoutoMaior, A. M. Validação de metodologia para a caracterização química de bagaço de canade-açúcar. Química Nova 2009, 32, 1500. [CrossRef]

${ }^{26}$ Silva, V. L.; Dissertação de Mestrado, Universidade Federal do Rio Grande do Norte, 2014. [Link]

${ }^{27}$ Silverstein, R. M; Webster, F. X; Kiemle, D. J.; Identificação Espectrométrica de Compostos Orgânicos, 7a. ed., LTC: Rio de Janeiro, 2007.

${ }^{28}$ Van Soest, P. J. Development of a compreheensive system of feed analysis and its application to forages. Journal of Animal Science 1967, 26, 119. [Link]

${ }^{29}$ Rodrigues, R. C. Métodos de análises bromatológicas de alimentos: métodos físicos, químicos e bromatológicos. 1a Ed., Pelotas: Embrapa Clima Temperado, 2010. [Link]

${ }^{30}$ Arruda, P. V.; Tese de Doutorado, Universidade de São Paulo, 2011. [Link]

${ }^{31}$ Esteves, P. J.; Dissertação de Mestrado, Universidade de São Paulo, 2011. [Link]

${ }^{32}$ Carvalho, M. L.; Dissertação de Mestrado, Universidade Federal de São Carlos, 2011. [Link]

${ }^{33}$ Fonseca, C. R.; Dissertação de Mestrado, Universidade de São Paulo, 2011. [Link]

${ }^{34}$ Fuentes, L. L. G.; Dissertação de Mestrado, Universidade Estadual de Campinas, 2009. [Link]

${ }^{35}$ Gomes, G. M. F.; Vasconcelos, A. M.; Egito, A. S.; Lima, A. R.; Carneiro, J. C.; Landim, A. V.; Fonteles, N. L. O.; Salles, H. O. Degradabilidade in situ do bagaço de canade-açúcar para pequenos ruminantes de raças naturalizadas do Nordeste brasileiro. Arquivo Brasileiro de Medicina Veterinária e Zootecnia 2013, 65, 1792. [CrossRef]

${ }^{36}$ Carvalho, de D. M.; Sevastyanova, O.; Penna, L. S.; da Silva, B. P.; Lindstrom, M. E.;
Colodette, J. L. Assessment of chemical transformation in eucalyptus, sugarcane bagasse and straw during hydrothermal, dilute acid, and alkaline pretreatments. Industrial Crops and Products 2015, 73, 118. [CrossRef]

${ }^{37}$ Palmqvist, E.; HÄgerdal, H. B. Fermentation of lignocellulosic hydrolysates. II: inhibitors and mechanisms of inhibition. BioResources Technology 2000, 74, 25. [CrossRef]

${ }^{38}$ Wang, Q.; Wang, Z.; Shein, F.; HU, J.; Sun, F.; Lili, L.; Yang, G.; Zhang, Y.; Deng, S. Pretreating lignocellulosic biomass by the concentrated phosphoric acid plus hydrogen peroxide (PHP) for enzymatic hydrolysis: Evoluating the pretreatment flexebility on feedstocks and particle sizes. Bioresource Techonology 2014, 166, 420. [CrossRef] [PubMed]

${ }^{39}$ Rezende, C. A.; Lima, M. A.; Maziero, P.; Azevedo, E. R.; Garcia, W.; Polikarpov, I. Chemical and morphological characterization of sugarcane bagasse submitted to delignification process for enhanced enzymatic digestibility. Biotechonolgy for Biofuels 2011, 4, 54. [CrossRef] [PubMed]

${ }^{40} \mathrm{Kim}, \mathrm{S}$.; Kim, C. H. Bioethanol production using the sequential acid/alkali-pretreated empty palm fruit bunch fiber. Renewable Energy 2013, 54, 150. [CrossRef]

${ }^{41}$ Chen, H.; Han, Y.; Xu, J. Simultaneous saccharification and fermentation of steam exploded wheat straw pretreated with alkaline peroxide. Process Biochemistry 2008, 43, 1462. [Link]

${ }^{42}$ Zhao, X.; Heide, E. V. D.; Zhang, T.; Liu, D. Delignification of sugarcane bagasse with alkali and peracetic acid and characterization of the pulp. BioResources 2010, 5, 1565. [Link]

${ }^{43}$ Yang, H.; Yan, R.; Chen, H.; Lee, H. D.; Zheng, C. Characteristics of hemicellulose, cellulose and lignin pyrolysis. Fuel 2007, 86, 1781. [Link] 